\title{
Patients affected with Fabry disease have an increased incidence of progressive hearing loss and sudden deafness: an investigation of twenty-two hemizygous male patients Dominique P Germain*1, Paul Avan², Augustin Chassaing ${ }^{1}$ and Pierre Bonfils ${ }^{3}$
}

Address: ${ }^{1}$ Department of Genetics, Hôpital Européen Georges Pompidou. 75015 Paris, France, 2 Auditory Research Laboratory. Faculté de Médecine, Université d'Auvergne, Clermont-Ferrand, France and ${ }^{3}$ Auditory Research Laboratory, Formation Associée Claude Bernard and CNRS UPRESSA 7060, Hôpital Européen Georges Pompidou. 75015 Paris, France

E-mail: Dominique P Germain* - dominique.germain@hop.egp.ap-hop-paris.fr; Paul Avan - paul.avan@u-clermont1.fr; Augustin Chassaing - augustin.chassaing@hop.egp.ap-hop-paris.fr; Pierre Bonfils - pierre.bonfils@hop.egp.ap-hop-paris.fr ${ }^{*}$ Corresponding author

Published: II October 2002

BMC Medical Genetics 2002, 3:10
Received: 3I July 2002

Accepted: II October 2002

This article is available from: http://www.biomedcentral.com/I47/-2350/3//0

(C) 2002 Germain et al; licensee BioMed Central Ltd. This article is published in Open Access: verbatim copying and redistribution of this article are permitted in all media for any purpose, provided this notice is preserved along with the article's original URL.

\begin{abstract}
Background: Fabry disease (FD, OMIM 30I500) is an X-linked inborn error of glycosphingolipid metabolism due to the deficient activity of alpha-galactosidase $A$, a lysosomal enzyme. While the progressive systemic deposition of uncleaved glycosphingolipids throughout the body is known to have protean clinical manifestations, few data are available regarding the cochlear involvement.

Methods: We non-invasively investigated cochlear functions in 22 consecutive hemizygous males (age 19-64 years, mean 39) affected with classic FD. Conventional audiometry, tympanometry, $A B R$ audiometry, otoacoustic emissions were performed in all patients, together with medical history record and physical examination as part of an exhaustive baseline evaluation prior to enzyme replacement therapy.

Results: A total of 12 patients (54.5\%) with classic FD were found to have abnormal audition. Five patients had progressive hearing loss and seven patients (32\%) experienced sudden deafness. In addition, a hearing loss on high-tone frequencies was found in 7 out of the 10 remaining patients without clinical impairment, despite their young age at time of examination. The incidence of hearing loss appeared significantly increased in $F D$ patients with kidney failure $(P<0.01)$ or cerebrovascular lesions $(P<0.01)$, whereas there was no correlation with left ventricular hypertrophy. In addition, tinnitus aurium was also found in six patients (27\%).

Conclusion: This is the first evidence of a high incidence of both progressive hearing loss and sudden deafness in a cohort of male patients affected with classic Fabry disease. The exact pathophysiologic mechanism(s) of the cochlear involvement deserves further studies.
\end{abstract}

\section{Background}

Fabry disease (FD, OMIM 301500) is an X-linked inherit- ed disorder of sphingolipids metabolism due to the deficient activity of $\alpha$-galactosidase A (EC EC 3.2.1.22), a 
lysosomal enzyme [1]. The enzyme deficiency leads to the widespread deposition of neutral glycosphingolipids (mainly globotriaosylceramide, and, to a lesser extent, galabiosylceramide) [2] in plasma and lysosomes throughout the body. Initial symptoms of FD include angiokeratoma, acroparesthesia, autonomic dysfunction, and corneal opacities. Progressive glycolipid deposition in the endothelial and smooth muscle cells of the microvasculature of affected patients leads to the narrowing and thrombosis of small arteries and arterioles, then to ischaemic complications involving brain, and heart, together with chronic renal insufficiency and early death [3-5].

Although FD is a paradigm for multi-systemic inherited disorder of metabolism, little is known about the pathogenesis of cochlear lesions and there has been a limited literature about cochleovestibular involvement in FD. One paper reported the histology of temporal bones in two patients [6], whose audiograms exhibited a bilateral sensorineural hearing loss audiometrically. Middle ear findings of seropurulent effusions and hyperplastic mucosa were seen in temporal bones of both patients. Strial and spiral ligament atrophy in all turns, and hair cell loss mainly in the basal turns, were also common findings. The number of spiral ganglion cells was reduced in all temporal bones. However, evidence of glycosphingolipid accumulation was not observed in the spiral ganglia [6].

Much interest is currently paid to emerging therapies, and recent studies have demonstrated that genetic engineering has removed many of the obstacles to the clinical use of enzyme replacement, and that infusions of purified $\alpha$-galactosidase A are safe and biochemically active $[7,8]$. However, the slow course of the disease emphasizes the need for development of clinical or surrogate endpoints, using non-invasive validated methodologies to delineate target organ damage and monitor the efficacy of emerging therapy with $\alpha$-galactosidase A on various endpoints.

In the present study, we hypothesized that the auditory functions could be altered in response to glycosphingolipid deposition. With this respect, we carried out a complete baseline auditory examination in a large cohort of 22 hemizygotes affected with Fabry disease, prior to enzyme replacement therapy.

\section{Methods}

\section{Subjects}

We examined 22 consecutive hemizygous male patients (19-64 years old, mean 39, SD 13.6) affected with classic FD from 17 unrelated pedigrees followed at the Clinical Genetics Unit of the Georges Pompidou European Hospital. All diagnose were made by one of us (DPG) from clinical features, and confirmed by demonstration of a 4methyl umbelliferyl- $\alpha$-galactosidase activity $<2.5 \mathrm{nmol} / \mathrm{h} /$ $\mathrm{mg}$ of proteins in peripheral blood leukocytes (normal values: $25-55 \mathrm{nmol} / \mathrm{h} / \mathrm{mg}$ of proteins). No results of examinations on any of our patients have been published previously.

The patients were referred to the Auditory Research Laboratory (PA, PB) for complete auditory examination as part of an extensive baseline evaluation before enzyme replacement therapy. Subjects with a history of trauma, otologic surgery, ototoxic reactions including aminoglycoside exposure, noise exposure, or concurrent medical conditions known to cause hearing loss were excluded from this analysis. There was no history of inherited deafness, unlinked to Fabry disease, in any of the 17 pedigrees. All subjects gave informed consent prior to participation.

\section{Audiologic evaluation}

All patients were studied in a quiet room with controlled temperature of $22 \pm 1^{\circ} \mathrm{C}$ by a unique senior investigator, trained and certified in ENT medicine (PB). Otolaryngological histories were obtained, and physical examinations, including pneumatic otoscopy, were performed on each subject. Audiologic evaluations consisted of puretone air and bone conduction audiometry, speech audiometry, and middle-ear immitance testing (tympanometry and acoustic reflex testing). All patients also underwent transient-evoked, distortion otoacoustic emissions testing, using an ILO96 Otodynamic analyzer previously validated in clinical studies (Otodynamics, London, England), and auditory brainstem response (ABR) audiometry using an Auris apparatus (Synapsys, Marseille, France).

\section{Clinical data analysis}

The type of hearing loss (HL) was classified as sensorineural, conductive, or mixed according to the European Working Group on Genetics of Hearing Impairment [http://www.gendeaf.org]. Conductive hearing loss was defined as normal bone conduction thresholds $(<20 \mathrm{~dB}$ $\mathrm{HL}$ ), and an average air-bone gap of $15 \mathrm{~dB}$ or more for 0.5 , 1 , and $2 \mathrm{kHz}$. Mixed hearing loss was defined as a bone conduction threshold greater than $20 \mathrm{~dB}$ HL in combination with an averaged air-bone gap $15 \mathrm{~dB}$ or more for 0.5, 1 and $2 \mathrm{kHz}$. Sensorineural hearing loss was defined as an averaged air-bone gap of less than $15 \mathrm{~dB}$ for $0.5,1$ and 2 $\mathrm{kHz}$.

The degree of hearing loss was categorized in two different ways: employment of commonly used age-independent clinical guidelines (International classification of impairments, disabilities and handicaps, World Health Organization, May 1980, Geneva, Switzerland) and comparison of thresholds to age-dependant percentiles $[9,10]$. For each ear, impairment was evaluated using pure-tone aver- 
Table I: Demographics and clinical characteristics of the study population

\begin{tabular}{|c|c|c|c|c|c|c|}
\hline Patient & Age & Acroparesthesia & $\begin{array}{c}\text { Kidney function (5I Cr-EDTA } \\
\text { Glomerular Filtration } \\
\text { Rate in } \mathrm{mL} / \mathrm{min} / 1.73 \mathrm{~m} 2)\end{array}$ & $\begin{array}{l}\text { Left ventricular } \\
\text { hypertrophy }\end{array}$ & $\begin{array}{l}\text { Central Nervous } \\
\text { System involvement }\end{array}$ & $\begin{array}{l}\text { Hearing status }(0-5) \\
* \text { right ear / left ear }\end{array}$ \\
\hline I & 50 & + & Transplant & + & + (lacuna on MRI) & $2 / 2$ \\
\hline 2 & 26 & + & Normal (98.7) & - & - & $0 / 0$ \\
\hline 3 & 40 & + & Transplant & - & - & $0 / 1$ \\
\hline 4 & 59 & + & Severe renal insufficiency (20.9) & + & $+(T I A)$ & $2 / 2$ \\
\hline 5 & 24 & + & Normal (87) & - & - & $0 / 0$ \\
\hline 6 & 34 & + & Transplant & + & - & $0 / 2$ \\
\hline 7 & 37 & - & Severe renal insufficiency (23.5) & - & + (stroke) & $2 / 5$ \\
\hline 8 & 29 & + & Normal $(111.8)$ & - & $+(\mathrm{TIA})$ & $0 / 0$ \\
\hline 9 & 48 & + & Transplant & + & $+($ Stroke $)$ & $5 / 2$ \\
\hline 10 & 40 & - & Transplant & + & - & $0 / 0$ \\
\hline 11 & 61 & - & Peritoneal dialysis & + & Not evaluated & $1 / 3$ \\
\hline 12 & 31 & + & Hemodialysis & + & $+($ stroke $)$ & $1 / 1$ \\
\hline 13 & 21 & + & Normal (127) & - & Not evaluated & $0 / 0$ \\
\hline 14 & 50 & + & Hemodialysis & + & + (lacuna on MRI) & $2 / 2$ \\
\hline 15 & 39 & - & Severe renal insufficiency ( 16.4$)$ & + & - & $0 / 0$ \\
\hline 16 & 23 & + & Normal (III) & - & $+(\mathrm{TIA})$ & $2 / 2$ \\
\hline 17 & 64 & + & Moderate kidney insufficiency (4I.2) & + & + (lacuna) & $0 / 1$ \\
\hline 18 & 36 & + & Normal (98.7) & - & - & $0 / 0$ \\
\hline 19 & 57 & + & Moderate kidney insufficiency (59.7) & + & $+(\mathrm{TIA})$ & $5 / 1$ \\
\hline 20 & 35 & - & Transplant & + & - & $1 / 1$ \\
\hline 21 & 28 & + & Mild kidney insufficiency (79.2) & - & - & $0 / 0$ \\
\hline 22 & 25 & + & Normal (I I4.2) & - & - & $0 / 0$ \\
\hline
\end{tabular}

Hearing impairment: 0: Normal hearing status (0-25 dB HL), I: mild impairment (26-40 dB HL); 2: moderate impairment (4I-55 dB HL), 3: severe deafness (56-70 dB HL), 4: profound deafness (9I-110 dB HL), 5: >1 $10 \mathrm{~dB}$ HL (cophosis)

ages (PTAs) for 0.5, 1, and $2 \mathrm{kHz}$. Impairment was audiometrically classified using the following pure-tone threshold ranges: normal 0 to $25 \mathrm{~dB} H \mathrm{HL}$; mild, 26 to $40 \mathrm{~dB}$ $\mathrm{HL}$, moderate, 41 to $55 \mathrm{~dB} \mathrm{HL}$; moderately severe, 56 to $70 \mathrm{~dB} \mathrm{HL}$; severe, 71 to $90 \mathrm{~dB} \mathrm{HL}$; and profound, 91 to $110 \mathrm{~dB}$ HL. Configuration of hearing loss was classified according to the European Working Group on Genetics of Hearing Impairment. Audiometric configurations were defined as midfrequency U-shaped, $15-\mathrm{dB}$ or more difference between the poorest thresholds in the midfrequencies and those at higher frequencies; low-frequency ascending, 15-dB or more from the poorest thresholds to the higher frequencies; flat, less than 15-dB between 0.25 and $8 \mathrm{kHz}$; high frequency, $15-\mathrm{dB}$ or more difference between the mean thresholds at 0.5 and $1 \mathrm{kHz}$ and the mean thresholds at 4 and $8 \mathrm{kHz}$. For each subject, impairment was classified using PTA on the more affected ear.

The age-dependent analysis of the degree of hearing loss plotted pure-tone air conduction thresholds at .5, 1, 2, and $4 \mathrm{kHz}$, and pure-tone averages (PTAs) for .5, 1, $2 \mathrm{kHz}$, against corresponding $95^{\text {th }}$ percentiles [9]. Similarly, pure-tone air conduction thresholds at $8 \mathrm{kHz}$ were plotted against corresponding $90^{\text {th }}$ percentile values [10]. Ninety- fifth percentile values for $0.5,1,2$ and $4 \mathrm{kHz}$ were obtained from a uniformly auditory screened population, and $90^{\text {th }}$ percentile values for $8 \mathrm{kHz}$ were obtained from the 1990 International Organization for Standardization standards. Ninetieth percentile values were chosen for 8 $\mathrm{kHz}$ owing to a lack of established $95^{\text {th }}$ percentile data for this frequency.

The percentage of study subjects with pure-tone thresholds above the $95^{\text {th }}$ percentile was calculated for all tested men. Bone-conduction thresholds were used for the analysis. The presence of sensorineural hearing loss was defined as two or more thresholds in one or both ears above the $95^{\text {th }}$ percentile value (for $0.5,1,2$ or $4 \mathrm{kHz}$ ), or the $90^{\text {th }}$ percentile value for $8 \mathrm{kHz}[9,10]$.

Tympanometric results were categorized according to standardized values for static compliance and tympanometric peak pressure [11].

\section{Statistical analysis}

Possible relations of hearing loss to other clinical symptoms were investigated by means of non parametrical tests (Mann-Whitney U tests) owing to the sample sizes $<30$, 
Table 2: Mean pure-tone averages (PTAs) and average air conduction thresholds from I $25 \mathrm{~Hz}$ to $8 \mathrm{kHz}$ as a function of age for affected individuals.

\begin{tabular}{|c|c|c|c|c|c|}
\hline Age group (years) & $21-30$ & $31-40$ & $4 I-50$ & $5 I-60$ & $61-70$ \\
\hline $\begin{array}{l}\text { Mean } \pm \text { SD (years) } \\
\text { Number of ears } \\
\text { PTAs, (dBHL) }\end{array}$ & $\begin{array}{c}25.1 \pm 2.6 \\
(n=14)\end{array}$ & $\begin{array}{l}36.6 \pm 3 \\
(n=16)\end{array}$ & $\begin{array}{l}50 \pm 0 \\
(n=4)\end{array}$ & $\begin{array}{c}58.3 \pm 0.5 \\
(n=6)\end{array}$ & $\begin{array}{c}62.5 \pm 1.7 \\
(n=4)\end{array}$ \\
\hline right ear & $15.9(11.9)$ & $19.6(13.8)$ & $45.8(10.6)$ & $100.6(33.7)$ & $23.3(14.1)$ \\
\hline left ear & $19(19)$ & $34(37)$ & $51.7(2.3)$ & $45.5(9.2)$ & $41.7(30.6)$ \\
\hline \multicolumn{6}{|c|}{ Air conduction thresholds } \\
\hline $125 \mathrm{~Hz}$ & $17.1(16.1)$ & $27.8(29.8)$ & $33.7(4.7)$ & $60(47)$ & $30(20.4)$ \\
\hline $250 \mathrm{~Hz}$ & $15.3(15.1)$ & $25.3(28.4)$ & $36.2(8.5)$ & $64.2(43.6)$ & $26.3(22.5)$ \\
\hline $500 \mathrm{~Hz}$ & $17.5(17.5)$ & $25.9(28.1)$ & $47.5(5)$ & $73.3(36.8)$ & $30(23.8)$ \\
\hline $\mathrm{I} \mathrm{kHz}$ & $16.1(13.7)$ & $25.6(28.5)$ & $46.2(7.5)$ & $74.2(36.1)$ & $33.7(21.7)$ \\
\hline $2 \mathrm{kHz}$ & $18.9(21.7)$ & $28.8(30.1)$ & 52.5 (II.9) & $71.7(39.3)$ & $33.7(22.8)$ \\
\hline $4 \mathrm{kHz}$ & $24.6(19.8)$ & $49.1(30.1)$ & $62.5(6.4)$ & $78.3(32.6)$ & $50(10.8)$ \\
\hline $8 \mathrm{kHz}$ & $32.1(31.8)$ & $60.6(27.6)$ & $67.5(8.7)$ & $89.2(25.4)$ & $66.3(20.2)$ \\
\hline
\end{tabular}

Data are given as mean (SD). DBHL = decibels hearing level.

comparing the observed hearing losses in two samples, namely an impaired and a healthy one relative to the clinical symptom of interest. $\mathrm{P}<0.05$ was considered significant. In the particular case of correlation between mean PTA and glomerular filtration rate, the scatterplot of data showed a strongly nonlinear relationship, with data points tending to cluster along the vertical and horizontal axes. In this case, patients were split into categories, respectively with normal and impaired hearing of glomerular filtration rate.

\section{Results}

\section{Demographics}

Our patients range from 19 to 64 years of age; the mean age at the time of examination was 39.5 (SD, 13.6) years old. Table 1 summarizes the major findings for the 22 hemizygous patients of our series.

\section{Auditory symptoms}

Ten subjects $(45.5 \%$, mean age $=34.8$ years, $\mathrm{SD}=12.4)$ considered their audition as normal. Five patients (mean age $=41.6$ years, $\mathrm{SD}=12.5$ ) complained of a progressive unilateral $(n=1)$ or bilateral $(n=4)$ deafness. Seven patients (mean age $=44.7, \mathrm{SD}=15.9$ ) complained of a sudden deafness: 4 patients had a sudden unilateral $(n=2)$ or bilateral $(\mathrm{n}=2)$ deafness, and 3 patients had an unilateral progressive deafness with a sudden deafness on the other ear. Six patients out of $22(27.3 \%)$ complained of tinnitus. Tinnitus occurred in the context of sudden deafness for 2 patients, and progressive hearing loss for 2 other patients. In the remaining 2 patients, audition was normal on the side with tinnitus.

\section{Age-independent analysis of hearing loss}

First, an age-independent analysis of the degree of hearing loss was realized using the age-independent clinical guideline published by the World Health Organization (International classification of impairments, disabilities, and handicaps, presented at: World Health Organization; May 1980; Geneva, Switzerland). Table 2 gives the mean air conduction thresholds and PTAs of all ears $(n=44$ ears), and their corresponding standard deviations (SD) versus the age of the affected subjects. All cases of deafness were sensorineural hearing losses. No conductive or mixed hearing loss was observed. Mean thresholds were within normal ranges for young patients (below 30 years old), and frequencies below $8 \mathrm{kHz}$, but increased with age and ranged from mild to severe in higher frequencies.

For each ear, impairment was audiometrically classified using the PTAs. Approximately 52\% (23 of the 44 ears) of all audiograms had strictly normal PTAs. Audiometric configurations of the remaining audiograms $(\mathrm{n}=21)$, according to the European Work Group on Genetics of Hearing Impairment, were mid-frequency U-shaped ( $\mathrm{n}=$ $1)$, flat $(\mathrm{n}=4)$, high-frequency hearing loss $(\mathrm{n}=13)$, and cophosis $(\mathrm{n}=3)$.

For each subject, impairment was audiometrically classified using the PTAs on the more affected ear. Figure 1 illustrates the degree of hearing loss of each subject as a function of age ( $\mathrm{n}=22$ subjects). Normal hearing was most common in the 21- to 30-year, and in the 31- to 40year age groups, whereas sensorineural hearing loss became more common in the older age groups. Most of patients after 41 years of age had a mild to profound hearing loss. Only $50 \%$ ( 11 of 22 ) of all affected subjects had strictly normal PTAs for both ears. 


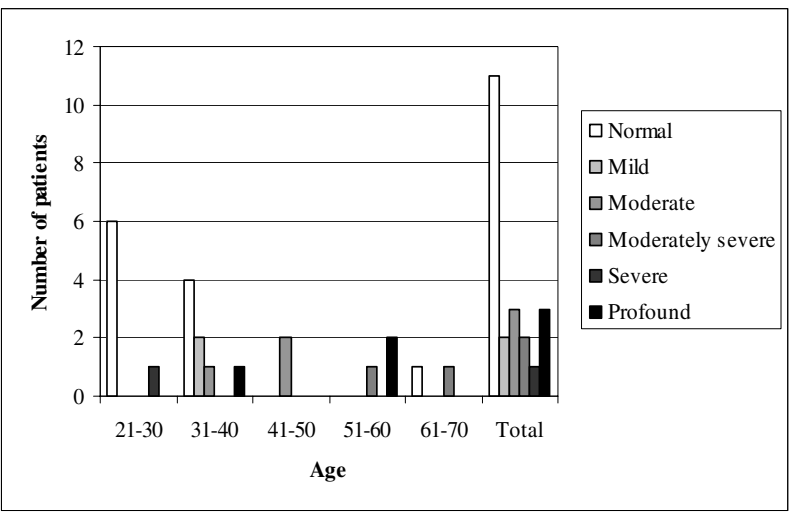

\section{Figure I}

Degree of hearing loss as a function of age in 22 patients affected with Fabry disease. Impairment was classified using pure-tone thresholds $(0.5, \mathrm{I}$, and $2 \mathrm{kHz}$; PTAs) on the more affected ear without any consideration with the age or higher frequencies ( 4 and $8 \mathrm{kHz}$ ).

\section{Comparison of thresholds to age-dependent percentiles}

To identify the contribution of Fabry disease to the observed sensorineural hearing loss, audiometric thresholds at $0.5,1,2,4$ and $8 \mathrm{kHz}$, as well as PTAs, were compared to those reported for an audiologically screened population 25 years and older [9,10]. As shown in Figure 2, 18 of the 22 patients $(82 \%)$ had at least two thresholds above the $95^{\text {th }}$ percentile (for $0.5,1,2$, and $4 \mathrm{kHz}$ frequencies) or, in the case of $8 \mathrm{kHz}$, above the $90^{\text {th }}$ percentile. Figure 3 shows the percentage of study subjects with pure-tone thresholds above the $95^{\text {th }}$ percentile (for $0.5,1,2,4$ frequencies and PTAs) and above the 90th percentile for 8 $\mathrm{kHz}$ frequency. The percentage of subjects with pure-tone thresholds above these limits varied from $56.8 \%(.5 \mathrm{kHz})$ to $86.4 \%(8 \mathrm{kHz})$.

\section{Sudden sensory hearing loss}

Sudden deafness may be defined as a sensorineural hearing loss that develops over a period of hours or a few days. Altogether, 7 patients (31.8\% of the patients, $20.5 \%$ of the tested ears) had episodes of sudden deafness.

Twenty-six-year-old patient AT $\left(\mathrm{n}^{\circ} 2\right)$ had bilateral sudden deafness two years ago, which partially reversed with a bitherapy (corticosteroids and vasodilatation). Auditory thresholds are now normal for all frequencies below 4 $\mathrm{kHz}$, but both high frequency hearing loss (70 dB HL at 8 $\mathrm{kHz}$ ) and bilateral tinnitus aurium remain. Thirty-sevenyear-old patient LO $\left(\mathrm{n}^{\circ} 7\right)$ had a left sudden deafness at age 12, leading to complete deafness without tinnitus. Forty-eight-year-old patient PG $\left(n^{\circ} 9\right)$ had a right sudden deafness at age 46, responsible for complete deafness without tinnitus aurium. Sixty-one-year-old patient FJ $\left(n^{\circ} 11\right)$ had a left sudden deafness at age 59, leading to a severe deafness (PTA $=60 \mathrm{~dB} \mathrm{HL}$, flat audiogram). Fiftyyear-old patient HD $\left(\mathrm{n}^{\circ} 14\right)$ had a left sudden deafness three months ago, leading to moderate deafness (PTA $=50$ $\mathrm{dBHL}$, high-frequency configuration). Patient JS ( $\left.{ }^{\circ} 16\right)$ had a right sudden deafness at only 23 years of age, with a subsequent residual hearing loss (PTA $=63 \mathrm{~dB} \mathrm{HL}, \mathrm{U}-$ shaped configuration). Fifty-seven-year-old patient PM $\left(n^{\circ} 19\right)$ had a right sudden deafness at age 43 , leading to complete deafness with tinnitus.

\section{Other findings}

All patients had type A tympanograms, indicative of normal middle ear mobility and pressure. Otoacoustic emissions (i.e., distortion product and transient-evoked otoacoustic emissions) were tested in all subjects, and revealed responses that were consistent with the degree of hearing loss [12,13]. As expected, emissions were absent in subjects with auditory thresholds above $30 \mathrm{~dB}$ HL in the range of 1 to $4 \mathrm{kHz}$. ABR audiometry was realized in all subjects, and revealed responses that were consistent with the degree of hearing loss. All intervals between waves I and V, and III and V were normal which precludes any significant retrocochlear involvement.

\section{Correlations}

\section{i) Kidney function}

Cochlear and kidney functions were compared for all 22 hemizygotes affected with classic FD. Kidney function was assessed by 51-Chrome-EDTA Glomerular Filtration Rate (GFR). Kidney insufficiency was classified into 4 groups: end-stage renal disease (GFR below $15 \mathrm{ml} / \mathrm{min} / 1.73 \mathrm{~m}^{2}$ ), severe kidney insufficiency (GFR between 16 and $30 \mathrm{ml} /$ $\min / 1.73 \mathrm{~m}^{2}$ ), moderate kidney insufficiency (GFR between 31 and $60 \mathrm{ml} / \mathrm{min} / 1.73 \mathrm{~m}^{2}$ ), normal kidney function (GFR above $61 \mathrm{ml} / \mathrm{min} / 1.73 \mathrm{~m}^{2}$ ).

Out of 22 patients, 9 patients had end-stage renal disease among which 3 were on dialysis and 6 had received kidney transplantation. Three patients had severe kidney insufficiency. Two patients had moderate kidney insufficiency. One patient had mild kidney insufficiency. Seven patients had normal kidney function. In summary, $67 \%$ of the patients in this series had an altered kidney function and $33 \%$ had a normal kidney function.

The mean bilateral PTAs $(0.5,1$, and $2 \mathrm{kHz})$ were compared to glomerular filtration rate. In all but two patients ( $\mathrm{n}=10$ ) with deafness (mean bilateral PTA $>25 \mathrm{~dB}$ HL), glomerular filtration rate was below $40 \mathrm{ml} / \mathrm{min} / 1.73 \mathrm{~m}^{2}$ (Figure 4$)$. In all but one patients $(n=8)$ with normal kidney function or mild kidney insufficiency (GFR above 60 $\mathrm{ml} / \mathrm{min} / 1.73 \mathrm{~m}^{2}$ ), PTAs were normal or below $20 \mathrm{~dB}$ HL. 

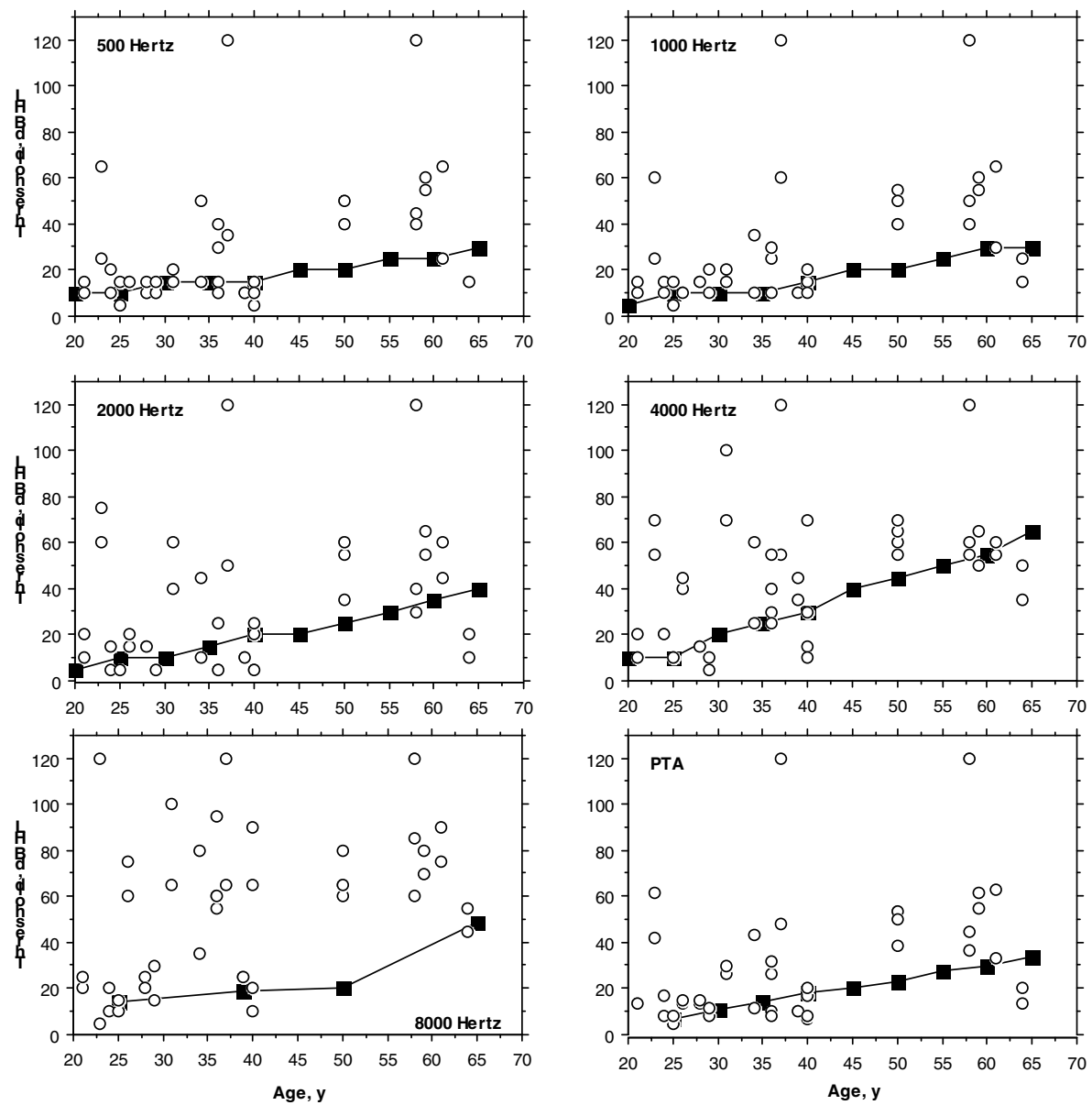

\section{Figure 2}

Comparison of thresholds for 20 Fabry hemizygotes, aged 25 years and older (circles), with $95^{\text {th }}$ percentile data (squares) from the International Organization for Standardization 1990 standards for 0.5, I, 2, 4 frequencies and PTAs or, for 8 kHz, with the $90^{\text {th }}$ percentile. $\mathrm{dB} \mathrm{HL}$ indicates decibel hearing level.

Out of 9 patients on dialysis or with kidney transplantation, only 2 had normal hearing (PTAs below $25 \mathrm{~dB} \mathrm{HL}$ ).

\section{ii) Cochlear and cerebrovascular manifestations of FD}

Patients were also classified according to their cerebrovascular manifestations. For correlation with hearing loss, the cerebrovascular involvement was classified into either absence or presence of any neurological clinical symptoms (strokes, transient ischaemic attacks) or magnetic resonance imaging (MRI) lesions (leukoareiosis or lacuna). Two patients who did not benefit from MRI were not included in the statistical analysis. Among the 20 studied hemizygotes with classic FD, 10 patients (50\%) had cerebrovascular disease, and 10 patients (50\%) had no symptoms or signs of cerebrovascular disease. A mean bilateral PTA of 14.9 dB HL ( $\mathrm{n}=10, \mathrm{SD}=7.9)$ was observed in patients with no cerebrovascular symptoms as compared to a mean PTA of $50.7 \mathrm{~dB}$ HL $(\mathrm{n}=10, \mathrm{SD}=26.5)$ in patients who had cerebrovascular involvement according to the above classification. Associations between cochlear and cerebrovascular involvement were analyzed using MannWhitney non parametric test. Cochlear involvement was significantly higher in FD patients with cerebrovascular involvement than in FD patients without $(P<0.01)$.

\section{iii) Cochlear manifestations of FD and left ventricular hypertrophy} Left ventricular hypertrophy (LVH) was defined as septal wall thickness $\geq 13 \mathrm{~mm}$ or posterior wall thickness $\geq 13$ $\mathrm{mm}$. Twelve patients (54.5\%) had left ventricular hypertrophy. A mean bilateral PTA of $23.4 \mathrm{~dB}$ HL $(\mathrm{n}=10, \mathrm{SD}=$ 24.9) was observed in patients without $\mathrm{LVH}$, whereas mean bilateral PTA was $40.3 \mathrm{~dB}$ HL $(\mathrm{n}=12, \mathrm{SD}=24.8)$ in patients with LVH. Using Mann-Whitney non-parametric test, no statistical difference was seen between the 2 groups $(P=0.3)$. 


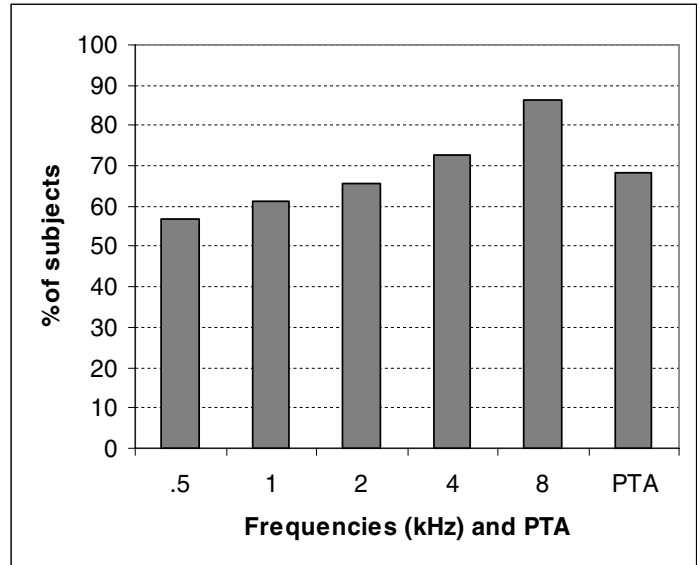

Figure 3

Percentage of study subjects with pure-tone thresholds above the $95^{\text {th }}$ percentile for the $0.5,1,2,4$ frequencies and PTAs, and above the $90^{\text {th }}$ percentile for the $8 \mathrm{kHz}$ frequency

\section{Discussion}

This study presents the first evidence of the high incidence of progressive hearing loss, sudden deafness, and tinnitus aurium in a cohort of 22 male patients affected with Fabry disease (FD), an orphan lysosomal storage disease. Fiftytwo percent of the patients complained of a progressive ( $\mathrm{n}$ $=5$ ) or sudden $(n=7)$ deafness, and 6 patients had tinnitus aurium. Approximately $82 \%$ of all patients had at least two auditory thresholds above the $95^{\text {th }}$ percentile for frequencies varying between 0.5 and $4 \mathrm{kHz}$, or above the $90^{\text {th }}$ percentile for the $8 \mathrm{kHz}$ frequency. All cases of deafness were sensorineural hearing losses.

The origin and the mechanisms of deafness probably involve the inner ear. In our study, no patient had conductive hearing loss, and all patients had type A tympanograms, in favor of normal middle ear mobility and pressure. Distortion products and transient-evoked otoacoustic emissions responses were consistent with the degree of hearing loss (i.e., absence of emissions in subjects with auditory thresholds above $30 \mathrm{~dB}$ hearing loss (HL) in the range of 1 to $4 \mathrm{kHz}$ ). In this study, ABR audiometry did not reveal any abnormality in intervals between waves I and V, and waves III and V. In the literature, clinical histories, audiometric results, and temporal histopathology were described [4] for two patients (48- and 59-year-old men) with FD [6]. Both patients demonstrated a bilateral sloping sensorineural hearing loss. Neuropathologic findings of the inner ear were major and identical. Evidence of glycosphingolipid accumulation in the ear in vascular endothelial cells, and in various ganglion cells, atrophy of the stria vascularis and the spiral liga-

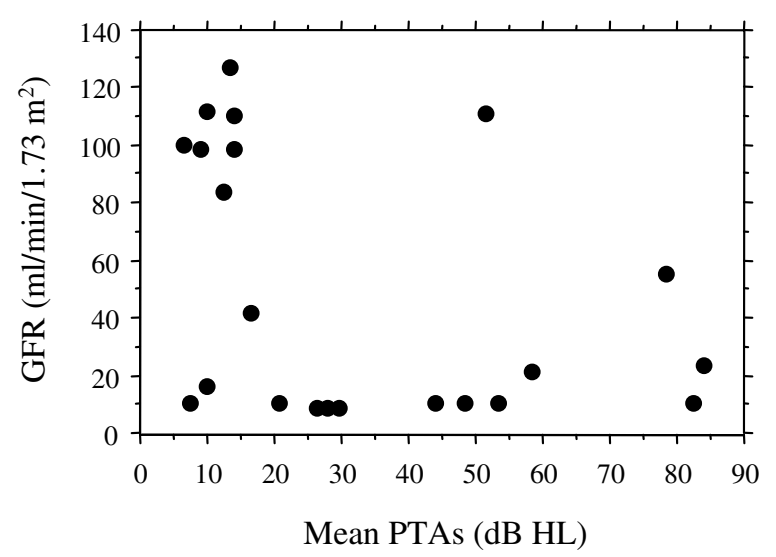

Figure 4

Glomerular filtration rate (GFR) against mean bilateral puretone averages $(0.5, \mathrm{I}$, and $2 \mathrm{kHz})$ in 22 hemizygotes affected with classic Fabry disease.

ment in all cochlear turns was observed in both cases. The authors concluded that hearing loss was caused by accumulation of glycosphingolipids within the stria vascularis and ganglion cells.

There could also be an endothelial or vascular component to deafness in FD patients, due to capillary wall hypertrophy, encroaching the lumen. Indeed, globotriaosylceramide (Gb3) accumulates in all cells of the body but has some key target sites of pathology, and deposition of glycosphingolipids occurs widely in the lysosomes of vascular endothelial and smooth-muscle cells [5]. Therefore, hearing loss and more specifically sudden deafness could also be potentially caused by vascular mechanisms due to the accumulation of glycosphingolipids within lysosomes of endothelial and smooth muscle cells leading to progressive narrowing, ischaemia, and frank occlusion in the vessels feeding the cochlea.

Finally, although intracellular Gb3 storage represents the initial insult to the cells, it is possible that a cascade of pathological mechanisms are involved in the development of disease-related complications, as suggested by recent studies which revealed an imbalance in vascular reactivity and the propensity for a pro-thrombotic state among patients with FD [14].

Interestingly, we found a correlation between kidney and cochlear involvement in our population. Most patients with hearing loss had a decreased glomerular filtration rate. Among our patients, 9 had severe renal insufficiency necessitating dialysis or kidney transplantation, and the 
responsibility of hemodialysis and renal transplant in the occurrence of hearing loss can be questioned. However, recent studies seem to indicate that neither dialysis nor renal transplant are the main cause of observed deafness in end-stage renal disease patients [15]. In our patients, the hearing loss was present in most cases before dialysis or transplant. However, it is still possible that both dialysis and transplantation could contribute to worsen a pre-existing hearing impairment. Cochlear lesions have been described in association with kidney insufficiency in various pathological situations, and pathophysiologic similarities have been observed between the kidney and the cochlea. One illustrating example is the common nephrotoxic and ototoxic component of various drugs or medicines (aminoglycosides, cisplatinum, furosemide...). For aminoglycosides the mechanism, although complex, seems to be related to lysosomal dysfunction. Aminoglycosides enter proximal epithelial cells of the kidney through endocytic vesicles which subsequently fuse with lysosomes. Aminoglycosides that resist to degradation can induce an alteration of the lysosomal phospholipase, a modified permeability of lysosomal membranes and a reduction in catabolism of renal proteins inducing phospholipidosis. A decrease of mitochondrial oxidative phosphorylation, an inhibition of the lysosomal membrane $\mathrm{Na} / \mathrm{K}+$ ATPase and the generation of superoxide anion and hydrogen peroxide were also observed. Similar mechanisms have been observed in the inner ear, specifically for outer hair cells [16] leading to sensorineural deafness, mainly on high tone frequencies. In FD, the lysosomal storage could trigger a similar mechanism with the epithelial cells of the kidney and the outer hair cells representing a key target site of pathology. Furosemide has also both ototoxic and nephrotoxic effects, inhibiting $\mathrm{Na} / \mathrm{K} / \mathrm{Cl}$ channels which are present on the renal tubular cells as well as the cells of the stria vascularis. Both examples appear interesting with respect to the clinical manifestations of FD, also affecting both the kidney and cochlea. Could similarities between the stria vascularis of the ear and the tubular cells of the kidney explain cochlear and kidney manifestations in FD through a common pathophysiology? Could ENT investigations allow to predict an evolution to end-stage renal disease in patients demonstrating hearing loss? These hypothesis necessitate further studies, among which examinations of histopathological specimens of the cochlea in patients affected with FD. Such histopathological pieces are however extremely rare, due to the rapid deterioration of cochlea after death, and only 2 patients have been described in the literature [6]. Histopathological studies of the cochlea obtained from the knock-out mouse models of FD could also potentially provide interesting data $[17,18]$.

FD is a multisystem disorder associated with a wide variability in clinical expression and one of the most devastat- ing features of FD are strokes or cerebrovascular accidents (CVA). In one study, the mean age at onset of cerebrovascular complications was 33.8 years and the commonest anatomical localisation for CVA was the vertebrobasilar territory with a high recurrence rate and reduced life expectancy [19]. Another study of 33 males reported the incidence of cerebrovascular complications as $24 \%$, with lesions localised to both the carotid and vertebrobasilar territories and occurring mostly before the age of 40 [20]. We observed a positive correlation between hearing loss and cerebrovascular accidents in our cohort of FD patients, further emphasising the importance of the vascular component as a likely mechanism for the occurrence of deafness in FD.

Data are available from several cohort studies, documenting a high frequency of left ventricular hypertrophy (LVH), concentric apical hypertrophy, and intraventricular septum thickening in FD [21-23]. Age-related progression of echocardiographic LVH changes, correlating with disease severity was reported in a cohort of young males, aged 14-43 years $(n=23)$ [24]. Out of the 22 patients evaluated in the present study, 12 (55\%) had LVH. Although we found a trend between cochlear involvement and LVH, statistical significance was not reached. Previous histopathological studies have shown that glycosphingolipid storage occurs in both cardiac capillaries and cardiomyocytes in classic FD. However, LVH is observed not only in the classic form but also in the cardiac variant of FD in which, interestingly, there is no storage in the vascular endothelium [5]. Therefore, the absence of statistically significant correlation between hearing loss and LVH could be in favour of different pathological mechanisms for these two lesions. Endothelial storage and dysfunction could be an important feature of the cochlear lesions, while LVH could be more related to storage in cardiomyocytes and subsequent dysfunction of metabolic pathways rather than to vascular involvement. However, our statistical analysis was limited to LVH (defined as septal wall thickness $\geq 13 \mathrm{~mm}$ or posterior wall thickness $\geq 13$ $\mathrm{mm}$, or cardiac mass $>130 \mathrm{~g} / \mathrm{m}^{2}$ ) assessed by echocardiography or cardiac MRI. It could be interesting to search whether a positive correlation between heart symptoms and hearing loss would appear when all cardiac manifestations including ECG modifications such as short PR interval, conduction abnormalities and rhythm disturbances are considered in the analysis.

Advances in the application of molecular genetic techniques have enabled development of directed protein therapies in Fabry disease. To a large extent, this milestone has resulted in a shift in the management paradigm offered to patients from an approach that relied on predictive genetic counseling and palliative care to the genuine possibility of offering early diagnosis and active interven- 
tion. However, the heterogeneity of clinical expression, the paucity of reliable markers and the uncertainty $a$ priori of being able to reverse the disease create a problem in the selection of the appropriate endpoints to evaluate the efficacy of therapeutic interventions $[7,8]$. Similarly, the decision to initiate enzyme replacement therapy (ERT) in asymptomatic patients is confounded by the variability of the phenotype and the absence of surrogate markers that reliably predict the pattern of organ involvement and disease severity. With this respect, our extensive evaluation of cochlear functions in a cohort of male patients affected with FD, demonstrating the high incidence of both progressive and sudden deafness, should prove useful in delineating the importance of cochlear lesions in the natural history of FD. We recommend an audiogram to be systematically performed in each FD patient prior to initiate ERT. Indeed, it could possibly serve as an additional endpoint for establishing whether enzyme replacement is effective in reducing or eliminating the incidence of FD-related hearing impairment. However, in view of the various possible mechanisms of hearing loss in FD, palliative measures may continue to be important in conjunction with ERT to achieve complete patient response or disease control, specifically if outer haired cells are destroyed.

Finally, we have also demonstrated that high tone deafness, usually not clinically significant but definitely confirmed by audiograms, was present at young age in hemizygotes. This is an important consideration because it is likely that delayed treatment, at a stage when advanced tissue changes (e.g., cochlear sclerosis or outer cells death) are established may not lead to full recovery and represent persistent sources of morbidity. This data further emphasize that early therapeutic intervention should offer increased possibilities of mitigating the disease process in Fabry disease [25].

\section{Conclusion}

This is the first evidence of a high incidence of both progressive hearing impairment and sudden deafness in a cohort of male patients affected with Fabry disease. Hearing loss on high-tone frequencies was also found on audiograms in Fabry patients with clinically "normal" audition, despite their young age at time of examination. The incidence of hearing loss appeared significantly increased in Fabry patients with kidney failure or cerebrovascular lesions.

\section{Competing interests \\ None declared}

\section{Authors' contributions}

Author 1 (DPG) conceived of the study, participated in its design and coordination, supervised $\mathrm{AC}$ and drafted the manuscript. Author 2 (PA) performed the statistical anal- ysis. Author 3 (AC) participated in the statistical analysis and in the draft of the manuscript. Author 4 (PB) conceived of the study, participated in its design and coordination, and drafted the manuscript.

All authors read and approved the final manuscript.

\section{References}

I. Brady RO, Gal AE, Bradley RM, Martensson E, Warshaw AL, Laster $L:$ Enzymatic defect in Fabry's disease: ceramide-trihexosidase deficiency. The New England Journal of Medicine 1967, 276: $1163-1167$

2. Sweeley CC, Klionsky B: Fabry's disease: classification as a sphingolipidosis and partial characterization of a novel glycolipid. Journal of Biological Chemistry 1963, 238:3148-3I50

3. Brady RO, Schiffmann R: Clinical features of and recent advances in therapy for Fabry disease. Journal of the American Medical Association 2000, 284:277|-2775

4. Germain DP: Fabry disease ( $\alpha$-galactosidase A deficiency) : Pathophysiology, clinical signs and genetics aspects. Journal de la Societe de Biologie 2002, 196:161-173

5. Desnick RJ, loannou YA, Eng CM: Alpha-galactosidase A deficiency : Fabry disease. In: The metabolic and molecular bases of inherited disease. (Edited by: Scriver CR, Beaudet AL, Sly WS, Valle D, Kinzler KE, Vogelstein B) New York: McGraw Hill 200I, 3733-3774

6. Schachern PA, Shea DA, Paparella MM, Yoon TH: Otologic histopathology of Fabry's disease. Annals of Otology Rhinology and Laryngology 1989, 98:359-363

7. Eng CM, Guffon N, Wilcox WR, Germain DP, Lee P, Waldeck S, Caplan L, Linthorst GE, Desnick RJ: Safety and efficacy of recombinant human $\alpha$-galactosidase $\mathbf{A}$ - replacement therapy in Fabry's disease. The New England Journal of Medicine 200I, 345:9-16

8. Schiffmann R, Kopp JB, Austin HA, Sabnis S, Moore DF, Weibel T, Balow JE, Brady RO: Enzyme replacement therapy in Fabry disease: a randomized controlled trial. JAMA 200I, 285:2743-2749

9. Morrell CH, Gordon-Salant S, Pearson JD, Brant LJ, Fozard JL: Ageand gender-specific references ranges for hearing level and longitudinal changes in hearing level. Journal of the Acoustic Society of America 1996, 100:1949-1967

10. Rosler G: Progression of hearing loss caused by occupational noise. Scandinavian Audiology 1994, 23:13-37

II. Jerger J: Clinical experience with impedance audiometry. Archives of Otolaryngoly, Head and Neck Surgery 1970, 92:3 I I-324

12. Gorga MP, Neely ST, Ohlrich B, Hoover B, Redner J, Peters J: From laboratory to clinic: a large scale study of distortion product otoacoustic emissions in ears with normal hearing and ears with hearing loss. Ear and Hearing 1997, 18:440-55

13. Avan P, Bonfils P, Loth D, Narcy P, Trotoux J: Quantitative assessment of human cochlear function by evoked otoacoustic emissions. Hearing Research 1991, 52:99-112

14. DeGraba T, Azhar S, Dignat-George F, Brown E, Boutiere B, Altarescu G, McCarron R, Schiffmann R: Profile of endothelial and leukocyte activation in Fabry patients. Annals of Neurology 2000, 47:229-233

15. Stavroulaki P, Nikolopoulos TP, Psarommatis I, Apostolopoulos N: Hearing evaluation with distortion-product otoacoustic emissions in young patients undergoing haemodialysis. Clinical Otolaryngoly 200 I, 26:235-242

16. Humes HD: Insights into ototoxicity. Analogies to nephrotoxicity. Annals of New-York Academy of Sciences 1999, 884:15-18

17. Brady RO, Murray G], Moore DF, Schiffmann R: Enzyme replacement therapy in Fabry disease. Journal of Inherited Metabolic Diseases 200I, 24:18-24

18. Ioannou YA, Zeidner KM, Gordon RE, Desnick RJ: Fabry disease: preclinical studies demonstrate the effectiveness of alphagalactosidase $A$ replacement in enzyme-deficient mice. American Journal of Human Genetics 2001, 68: 14-25

19. Morgan SH, Rudge P, Smith SJM, Browstein AM, Kendall BE, Holly E, Young EP, Crawfurd MdA, Bannister R: The neurological complications of Anderson-Fabry disease ( $\alpha$-Galactosidase A deficiency). Investigation of symptomatic and presymptomatic patients. Quarterly Journal of Medicine 1990, 75:49I-504 
20. Mitsias P, Levine SL: Cerebrovascular complications of Fabry's disease. Annals of Neurology 1996, 40:8-17

21. Linhart A, Palecek T, Bultas J, Ferguson J], Hrudova J, Karetova D, Zeman J, Ledvinova J, Poupetova H, Elleder M, Aschermann M: New insights in cardiac structural changes in patients with Fabry's disease. American Heart Journal 2000, I39: I 10I-I I08

22. Linhart A, Lubanda JC, Palecek T, Bultas J, Karetova D, Ledvinova J, Elleder M, Aschermann M: Cardiac manifestations in Fabry disease. Journal of Inherited Metabolic Diseases 200I, 24:75-83discussion 65

23. Senechal M, Germain DP: Fabry Disease: A functional and anatomical study of cardiac manifestations in 20 hemizygous male patients. Clinical Genetics

24. Goldman ME, Cantor R, Schwartz MF, Baker M, Desnick RJ: Echocardiographic abnormalities and disease severity in Fabry's disease. Journal of the American College of Cardiologists 1986, 7:|1157-|16|

25. Germain DP: Fabry disease: recent advances in enzyme replacement therapy. Expert Opinion in Investigational Drugs 2002, II:1467-1476

\section{Pre-publication history}

The pre-publication history for this paper can be accessed here:

http://www.biomedcentral.com/1471-2350/3/10/prepub

Publish with BioMed Central and every scientist can read your work free of charge

"BioMedcentral will be the most significant development for disseminating the results of biomedical research in our lifetime."

$$
\text { Paul Nurse, Director-General, Imperial Cancer Research Fund }
$$

Publish with BMC and your research papers will be:

- available free of charge to the entire biomedical community

- peer reviewed and published immediately upon acceptance

- cited in PubMed and archived on PubMed Central

- yours - you keep the copyright
BioMedcentral.com editorial@biomedcentral.com 